\title{
ECLAC and the new growth theories
}

\section{Adela Hounie} Lucía Pittaluga

Research Fellows in the

Institute of Economics,

Faculty of Economic and

Management Sciences,

University of the Oriental

Republic of Uruguay.

\section{Gabriel Porcile} Fabio Scatolin

Professors,

Department of Economics, Federal University of Paraná, Brazil.
This article reviews various different growth models, with emphasis on the interactions between economies with differing degrees of technological development. It takes as its starting point the proposals put forward by ECLAC in the 1950s (section II); as subsequent proposals by ECLAC in the 1980s and 1990s have incorporated various contributions made by more recent models it may be asserted that the evolution of ECLAC's ideas likewise illustrates the evolution of economic growth theory in general. It then goes on to analyse endogenous growth models with monopolistic competition conditions of the neoclassical school (section III), presents Schumpeterian models of what has been called the "evolutionary school" (section IV), and describes the thinking of the "new ECLAC" of the 1980s and 1990s and its conceptual and propositional renewal (section V). It then compares the different models and approaches analysed in the light of some aspects considered to be of key importance, such as the role assigned to endogenous technical progress in explaining long-term economic growth, the way the different conceptions of technology condition the nature of public intervention to promote development, and the validity of the concepts of bipolarity and/or international divergence with respect to the long-term growth rates of the per capita product (section VI). The final considerations (section VII) contain some reflections on aspects relating to development policies, both from the standpoint of the various approaches reviewed earlier and from that of the special structural features typical of the Latin American economies. 


\section{I}

\section{Introduction}

Since the mid-1980s -partly because of the appearance of new growth models- there has been a revival of interest in the processes of convergence or divergence of the growth rates of the product or of per capita income between the different economies. This study proposes to review those models ${ }^{1}$ from a perspective which stresses the interactions of economies with different degrees of technological development.

As our starting point, we have taken the ideas and proposals made by ECLAC in the 1950s, which are referred to in section II. This starting point was selected for three reasons. The first is that ECLAC played a pioneering role in the study of the North-South or Centre-Periphery economic dynamics, to use its own terminology. The second reason is connected with the emphasis placed in the initial ECLAC position on technical progress and its key role in international convergence or divergence. Indeed, this was to become one of the leading items in more recent models. Finally, there is the fact that the "New ECLAC" -that of the 1980s and 1990s, which is dealt with in section $\mathrm{V}$ - has incorporated various contributions from those models. Thus, it may be asserted in general terms that the evolution of ECLAC's ideas illustrates the evolution of economic growth theory as a whole.

Section III analyses the changes in neo-classical growth theory. In this theory, Solow's model, which had a decisive influence up to the mid-1980s and is to a large extent typical of it, attributed long-term growth to an exogenous variable: technical progress (Solow, 1956). More recent theories, called

$\square$ The authors wish to express their gratitude to Octavio Rodríguez for his support in the preparation of this study, and to Oscar Burgueño for his collaboration in various discussions on this subject. Both these academics are researchers in the Institute of Economics of the Faculty of Economic and Management Sciences of the University of the Oriental Republic of Uruguay. It goes without saying, however, that the views expressed here are entirely the responsibility of the authors.

1 The term "model" is used here in a similar sense to that given to it by Schumpeter and therefore includes analytical formulations in any language: not just that of mathematics (see, in this respect, Vercelli, 1991, p. 15). "endogenous growth theories", in contrast, seek to take this variable into account by relating it with the decisions of the economic agents on investment in technology. By doing this, they arrive at results which, like the earliest ECLAC approach, allow for possible systemic divergences between the growth rates of different countries which cannot be addressed through the conventional models.

Section IV presents the Schumpeterian models of the "evolutionary" school. These models -especially those that use simulation techniquesseek to incorporate more fully the diversities of technological level and behaviour which exist among firms and countries. The evolutionary school is also marked by the importance it assigns to the institutional framework in which technical progress takes place and the important role of demand in economic growth. It is argued in the present article that the models of this school point out some of the most promising directions for research, partly because of the greater breadth and realism of their basic assumptions and partly because of the flexibility with which these assumptions can be adapted for the analysis of complex situations.

Section V deals with the ideas of the "New ECLAC", as already noted in the paragraph above concerning section II, and their receptiveness to the new economic growth theories.

Section VI analyses and compares the different models and approaches presented, in the light of some aspects considered to be of key importance, such as the role attributed to endogenous technical progress in explaining long-term economic growth; the way in which the different conceptions of technology condition the nature of public intervention in the promotion of development and, finally, the validity of the concepts of bipolarity and/or international divergence in the long-term growth rates of the per capita product.

Finally, section VII reflects on some aspects relating to development policies, both from the angle of the different perspectives involved and from the standpoint of the specific structural features of Latin American economies. 


\section{II}

\section{The bipolarity between centre and periphery}

In his 1948 "manifesto", Raúl Prebisch ascribed the differences between the level of development of a group of countries which he termed "central" and the countries which he termed "peripheral" to the slow and uneven spread of technical progress through the international economy. ${ }^{2}$

The essence of his seminal ideas may be summed up, very briefly, as follows: ${ }^{3}$ There are two groups of countries, differentiated by the characteristics of their respective economic structures, which form the two poles of a single system. One of them -the centrehas a diversified and homogeneous productive and economic structure: ${ }^{4}$ diversified, because it is made up of a relatively broad spectrum of economic activities, and homogeneous, because labour productivity levels are relatively similar in all those activities. The periphery, in contrast, occupies a place in the world economy based on specialization in primary commodity production for export and therefore tends to display a narrower range of activities (for example, it starts off by lacking a significant industrial sector). In some of these activities, labour productivity is high because of the penetration of technical progress. A large proportion of the labour force, however, continues to work at jobs of very low productivity, thus giving rise to a situation of structural heterogeneity.

\footnotetext{
2 At that time, Prebisch's document entitled "The economic development of Latin America and its principal problems" came to be called the "ECLAC Manifesto". In it, the "slow and uneven spread of technical progress" was linked for the first time with the unequal or bipolar nature of development in the centre-periphery system. This document was also published later in the Economic Bulletin for Latin America (Prebisch, 1962).

${ }^{3}$ The body of ideas of ECLAC has been dealt with in detail in various documents (Furtado, 1985; Rodríguez, 1981; Bielschowsky, 1988). In this article, we will limit ourselves to presenting a very brief summary.

4 The expression "productive structure" refers to the composition of the output of material goods. The economic structure includes, in addition, the production of various kinds of services, including public goods and services.
}

In contrast with that of the centres, then, the production structure of the periphery is initially heterogeneous and specialized, and this difference persists in the spontaneous industrialization process sparked off in the periphery by the crisis of the 1930s and the Second World War. The basic reason for this is that technical progress -which is more intense in industry than in primary production- is likewise uneven between the two poles.

The disparity in the rates of generation and incorporation of technical progress, associated with the initial specialization, means that the spontaneous industrialization of the periphery begins with the production of technologically simple manufactures and gradually progresses towards the production of industrial goods of growing technological complexity. This pattern of industrialization, which progresses from simple to more complex goods through import substitution, means that while the production structure of the periphery gradually changes, it nevertheless remains essentially specialized (for example, in terms of the degree of intersectoral complementarity and vertical integration of manufacturing activities). This repetition of specialization lies at the root of the trend towards external imbalance, which is due ultimately to the fact that import substitution industrialization itself generates snowballing increases in the demand for imports, while primary commodity exports grow only slowly. ${ }^{5}$

Spontaneous industrialization brings with it an increase in employment, both in manufacturing and in the other modern activities which grow up along with it. However, this increase in the demand for labour does not match the increase in its supply, because the latter is due to the number of workers attracted to the cities and, even more so, the labour

\footnotetext{
${ }^{5}$ The structural reasons for the external imbalance referred to in this paragraph are usually presented in terms of the well-known argument of the disparity between the income-elasticities of demand for the imports and the exports of the periphery.
} 
displaced from low-productivity activities as a result of the modernization of agricultural activities.

The result is that the heterogeneity is repeated too, but this process does not take place without changes, in what has been called "inward-looking development". In this phase, the heterogeneity and the tendency towards structural underemployment which reflects it are increasingly evident in urban areas, through what has come to be known as marginality or informality.

It could be said, then, that according to the original ECLAC conception specialization is the underlying reason for external imbalance, while heterogeneity lies at the root of structural underemployment. This conception also holds that these two structural conditions give rise, together, to a third tendency: deterioration in the terms of trade.

Increases in labour productivity are more marked in the central countries, where the relative scarcity of labour and workers' capacity for organizing themselves in trade unions cause increases in productivity to be reflected in higher wages. For the opposite reasons, the opposite takes place in the periphery, and the resulting differences in wages are reflected -through mechanisms which need not be discussed here- in a decline in the relative prices of the periphery's exports compared with those of its imports which come from the central countries.

Prebisch holds that this deterioration in the terms of trade is the visible expression of a deeper phenomenon: the concentration of the fruits of technical progress in the great industrial centres. This means that in those countries the per capita income tends to grow more than labour productivity, because they take advantage of part of the increases in productivity registered in the periphery. In contrast, per capita income in the periphery tends to grow less than productivity because the peripheral countries transfer part of their increased productivity to the centres, through the deterioration in the relative prices of their exports.

We have just referred, above, to the differences in income. These represent the first and most directly visible aspect of the bipolarity inherent in the development of the centre-periphery system. The second salient aspect is the differences between their productive and economic systems, which tend to persist or, if you prefer, to be reproduced in new forms.

However, such bipolarity -"divergence", as it is called nowadays- is not seen as an inevitable phenomenon. In order to avoid it, the development process of the periphery needs to be directed along certain lines, the most important of which is industrialization. In other words, it is maintained that by applying suitable long-term policies it will be possible to bring about gradual "convergence" between the two poles of the system, with beneficial effects for the world economy as a whole. It may be gathered from this that the question of convergence or divergence lies at the very heart of the original ECLAC ideas and proposals. We will return to this matter later.

\section{III}

\section{Neoclassical growth theories}

In this section we will briefly contrast the traditional versions of neoclassical growth models with what have come to be known as "endogenous growth models" and we will also briefly describe some models of this type which include monopolistic competition among their key assumptions. We will then enter in greater detail into the conception of technology used in the new models and, finally, analyse the connotations of this conception as it affects both convergence or divergence of the per capita product among different economies and international trade and public policies.

\section{Endogenous growth models}

In their traditional versions (Solow, 1956 and 1957), the neoclassical models start out in general by assuming the existence of a production function with two factors -labour and capital- with constant yields to scale and decreasing returns on each factor. These models aim to show that, in the absence of technical progress, in the long term the growth rate of the per capita GDP will tend to decline to zero.

This tendency is connected with the decreasing nature of the marginal productivity of capital, for this 
assumption means that the accumulation of this factor will bring with a decline in its yield, thus discouraging real investment. In the long term, the latter will barely be sufficient to cover the depreciation of the existing capital stock and the provision of equipment for the new labour entering the production process. This gives rise to a steady-growth state in which the product grows at the same rate as the active population. In contrast with this basic reasoning, the models in question show that in order to achieve a higher growth rate which will enable the per capita product to register sustained growth, technological change exogenous to the economic system will be required.

This exogenous nature of the change assumes that technical progress takes place without the intervention of the economic agents. The new endogenous growth models reject this exogenous character and likewise question the decreasing nature of the marginal returns on accumulable factors such as physical and human capital. ${ }^{6}$ These models assume, on the one hand, a context of imperfect competition which makes possible remuneration of intentional innovation by private entrepreneurs, while on the other they assume that the externalities generated by this innovation obviate convergence of the growth rate of the product towards that of the active population.

Among the models mentioned, the first example that springs to mind is that of Romer (see Appendix 1). In this model (Romer, 1990), economic growth comes from the heightening of the division of labour achieved through the incorporation of technical progress, which is reflected in the creation of new varieties of capital goods which are neither better nor worse than the existing ones. ${ }^{7}$ In this model, then, technical progress operates through the horizontal differentiation of such goods. This wider range of capital goods makes it possible to increase the social

\footnotetext{
${ }^{6}$ For the purposes of this article, it is sufficient to consider the models that incorporate monopolistic competition in the analysis, since they are the same ones that see technical progress as endogenous. We shall refer to this again later on. Among the models which have been excluded from consideration are those of Jones and Manuelli (1990) and Rebelo (1991), which consider the accumulation of physical and human capital to be the mainspring of growth, and the studies by Lucas (1988), among others, in which the sustainability of growth is linked with the accumulation of inputs that generate positive externalities.

${ }^{7}$ In other words, Romer introduces a simplifying assumption that there is no obsolescence of capital goods.
}

division of labour, permitting each producer of final goods to find the most suitable instruments for the purpose which will give him greater productivity of physical capital, human capital and unskilled labour.

In the model by Aghion and Howitt (1992), growth comes directly from technical progress, which is in turn the result of competition among the firms that produce innovations. Each innovation generates a new type of capital good whose use will improve the productivity of the manufacturer of the corresponding final good. In contrast with Romer's model, in this model the new capital good takes the place of the previous one, giving rise to a process of "creative destruction". It is understood that technical progress creates profits but also losses, since production processes, products, skills, markets and areas of competitiveness are made obsolete, and it may be that the losses outweigh the gains. Moreover -also in contrast with Romer's model, where innovation takes place through incremental improvements- it is understood that innovation takes place through radical shocks in the economic systems. ${ }^{8}$

The third model to be considered is that of Grossman and Helpman (1991, chap. 3), in which technical progress takes place essentially through expansion of the variety of goods produced. In an innovative economy, knowledge (as measured by the quantity of designs of different goods) increases with time, increasing the productivity of the resources used in research laboratories. ${ }^{9}$ Furthermore, a substantial part of the knowledge accumulated in the research and development (R\&D) process can be used by other agents at no cost to them. Within the context of the model in question, this phenomenon plays a central role in explaining sustained long-term growth.

Each new product imperfectly replaces the previous ones. It is also assumed that companies are the only ones to possess the technology needed to manufacture a unique differentiated product, thus having monopoly power in the supply of that good. ${ }^{10}$

\footnotetext{
${ }^{8}$ It should be noted that in this model the time interval between two innovations is a random variable, with the probability of occurrence of an innovation depending on processes subject to a Poisson-type distribution.

9 This assumes that there is a learning process in research activities or in the practice of conducting research.

${ }^{10}$ The authors in question also propose other models in which technical progress is reflected in goods of better quality which take the place of the previous ones, thus eliminating the monopoly power of entrepreneurs manufacturing goods of lower quality.
} 
Assuming a given quantity of resources, the model is developed on the basis of a trade-off in the allocation of those resources between R\&D activities and the manufacture of high-technology products. The rate of innovation can be increased by allocating more resources to $R \& D$ at the expense of manufacturing, up to the point at which the opportunity costs of the two activities become equal. When this point is reached, the economy will attain a state of dynamic equilibrium, with positive and constant rates of innovation and growth and with a distribution of resources between $R \& D$ and manufacturing which is maintained over time.

It is important to note that, leaving aside their special features, the three models considered can give path-times for growth which may vary according to the basic conditions of each economy but which depend ultimately on the rate of technical progress deriving from the manner of operation of each economic system. This endogenization of technical progress is closely related with the way such progress is conceived, which is dealt with in the following section. The possible paths also have implications for the convergence or divergence between economies, international trade and public policies: matters which are dealt with in section 3 below.

\section{Technology as an economic good, and its implications}

Endogenous growth models consider technological knowledge as a non-pure public good, because of its dual character of a non-rival and partially exclusible good. Its non-rivality is associated with the possibility of using it in one economic activity without preventing or reducing its simultaneous use in another. In other words, it is understood that technological knowledge can be used by an indeterminate number of firms for innumerable periods of time, without depletion or additional costs. The partially exclusible nature of a technology means that its creator can only appropriate part of its economic results. The other part consists of externalities or technological spillover: i.e., the free and automatic acquisition of knowledge created by other enterprises. This spillover exists because although a patent or secrecy prevent others from making unauthorized use of new knowledge, this exclusion is only temporary, and moreover there are certain aspects of knowledge which are not susceptible to exclusion.

In contrast with traditional growth theories, this new conception of technology makes it possible to construct models incorporating endogenous technical progress and sustained growth of the per capita product. These models incorporate, on the one hand, a framework of monopolistic competition, in order to justify private investment in $R \& D$, and on the other hand, the externalities that may be associated with the creation of general technological knowledge, which is the prime source of sustained growth. These two aspects will be analysed in the following sections.

a) Innovation and monopolistic competition

In order to explain how private enterprises that generate technological knowledge behave, we must abandon the usual assumption of the competitive nature of markets and admit that their structure takes on special features because of monopolistic competition. The key to this reasoning is the partially exclusible and non-rival nature of the technology.

In order for an entrepreneur to be willing to innovate, he must be able to appropriate some of the income associated with technological knowledge. If the latter is non-exclusible, there will be no way to effect such appropriation. If a good is partially exclusible, however, a private generator of technology can prevent others from using it freely for a time, either through a patent or through secrecy. This is what determines if an entrepreneur can obtain a monopoly rent after innovation.

In traditional neoclassical models, the conditions in which production activities are carried out in any enterprise are represented by a homogeneous production function with a degree of unity. With this type of function, if the amount of resources is doubled and exactly the same sequence of productive actions are carried out, the amount produced will also be doubled. In other words, there will be constant returns to scale. ${ }^{11}$

\footnotetext{
${ }^{11}$ Formally, if $Y=F(K, H, L)$ is a function of the type in question, in which $K, H$ and $L$ represent respectively physical capital, human capital and labour, then $F(\lambda K, \lambda H, \lambda L)$ $=\lambda F(K, H, L)$.
} 
In the new neoclassical models, technological knowledge becomes a non-rival factor of production. As already noted, because of this it can be used again and again without depletion or additional cost. A production activity of this nature is represented by a production function with increasing returns to scale. ${ }^{12}$

As the latter are expressed in a homogeneous function with a degree greater than unity, this ensures the existence of sufficient resources to remunerate technological activities. ${ }^{13}$

In short, enterprises that generate technology will not be able to survive unless they can receive monopoly rents. The exclusibility of knowledge -even if only partial- permits the appropriation of this additional income associated with innovation, while the non-rivality of technological knowledge is reflected in production functions with increasing returns to scale, so that firms can sell their products at prices above the marginal production costs.

\section{b) Technological externalities and growth}

At the aggregate level of the economy as a whole, the fundamental idea of the models analysed here is that imperfect appropriation and non-rivality make possible the wide dissemination of technological knowledge. These technological externalities give rise to sustained growth of per capita GDP. Thus, in contrast with the traditional models, in the new models such growth is an endogenous result of the functioning of the economic system.

The models in question distinguish between specific and general knowledge, both derived from the $R \& D$ carried out in private firms. Specific knowledge permits a firm to manufacture a particular product or incorporate a particular production process. This is the type of knowledge which can be temporarily protected by patents or secrecy, which makes it an exclusible economic good. General knowledge, in contrast, is of broader application and

\footnotetext{
12 Formally, if $F(A, R)$ represents a production function where $R$ denotes the rival inputs $K, H$ and $L$ and $A$ denotes a non-rival input, the non-rivality of the latter will mean that $F(\lambda A, \lambda R)>$ $\lambda F(A, R)$.

${ }^{13}$ It should be recalled that, when constant returns to scale are expressed as a homogeneous production function with a degree of unity, payment to factors according to their respective levels of marginal productivity depletes the exact value of the product without taking away resources that could serve to remunerate innovation.
}

is much more difficult to exclude, as it is much harder to invoke universal principles and use the existing legislation to legitimize the ownership of this type of knowledge. The novel feature incorporated by endogenous growth theory is, precisely, that it recognizes the existence of externalities in respect of general knowledge resulting from private $\mathrm{R} \& \mathrm{D}$ efforts.

Such technological spillover gives rise, on the one hand, to growing returns from the accumulation of technological knowledge, and on the other to increases in the productivity of rival factors of production. With regard to the first of these effects, it is shown that each researcher's function of production of knowledge helps to increase the productivity of all the others, who will have these discoveries at their disposal in the long run. The externalities take place not only between contemporaneous agents, but also over the course of time. In other words, each innovation is an addition to the stock of existing knowledge, which, moreover, is not depleted. It can therefore be asserted that the marginal product of research activity increases in proportion as that stock grows. $^{14}$

The second effect is connected with the capacity of technological knowledge to act on each and every one of the other inputs, so that the relation between the amount of product obtained per unit of input is greater when the latter is used in combination with new knowledge. This effect makes it possible to compensate for the tendency towards decreasing marginal returns on accumulable factors such as physical and human capital, thus resulting in sustained growth of the per capita product.

\section{The implications of the new theories}

We will now analyse the way these models visualize the relations between economies at different levels of technological development and the ways in which these relations affect the capacity to incorporate technology and grow, as well as the role these models assign to public policies.

\footnotetext{
${ }^{14}$ Formally, this may be represented by the equation $a=f(A)$, where $a$ is the amount of discoveries made by a researcher over a certain period, $A$ is the stock of available knowledge, and $f$ is a growing function. This representation may be made more complex by introducing, for example, a random variable for the length of duration of the research (Aghion and Howitt, 1992).
} 
a) Convergence or divergence?

Traditional neoclassical models predict what they call "conditional convergence". This expression means that the per capita income growth rate of each economy converges towards its own steady growth value and also towards the per capita income levels of the other economies. The word "conditional" refers to the fact that this convergence also depends on the different economies having certain similar parameters, such as rates of saving, of capital depreciation or of population growth. ${ }^{15}$

In contrast, by abandoning the hypothesis of equality of technological opportunities between countries or regions, the advocates of endogenous growth theories find that it is not possible to predict convergence on the basis of their models. The result will depend on the effect of the spread of technology on the growth of the various economies.

In the models of Grossman and Helpman (1991), in principle the free spread of "general" technological knowledge benefits both firms in the country where the new knowledge is generated and those in other countries too. However, the international spread of the new knowledge takes place with lags due to legal and cultural barriers that inhibit the free circulation of persons and ideas across national frontiers. The international or national reach of this technological spillover and its rate of spread will directly affect the possibilities of economic convergence among nations.

"Specific" knowledge, for its part, can spread through imitation. There will be entrepreneurs who are interested in imitating a new product or process, provided that the expected rent exceeds the costs by a suitable margin, which will depend to a crucial extent on the incidence of the patents system on those costs.

\footnotetext{
${ }^{15}$ For example, Mankiw, Romer and Weil (1992) have found that the international disparity of per capita income levels and growth rates is consistent with Solow's standard model, modified by the inclusion of human capital as an accumulable factor and by the possibility that different countries may have different rates of saving. Barro and Sala-i-Martin (1995), for their part, found that there was convergence of levels of per capita income or product between the different states of the United States (1880 to 1990), between 47 Japanese prefectures (1930 to 1990) and between 90 regions of 11 European countries (1950 to 1990).
}

The possibilities opened up by imitation have analytical implications that affect North-South relations regarding the dissemination of technology. Thus, Grossman and Helpman (1991, chap. 11) have prepared a specific model on this matter, in which it is assumed that the South does not innovate itself but imitates technologies generated in the North. Such imitation is not exempt from costs, however: the learning process needed to master new technologies calls for efforts in the form of investments in technological capacity. The spillovers generated by these investments allow the South to accumulate a stock of knowledge which grows with its experience in imitation, which is associated with the amount of technology copied from the North. The technological lag of the South therefore has some positive aspects in the form of the growth possibilities opened up by the lower cost of imitative rather than innovative $\mathrm{R} \& \mathrm{D} .^{16}$

International trade also affects the possibilities of convergence among nations. For the purposes of this article, cases of particular interest are those where the production factor endowments differ, and especially those where there are differences in the endowments of skilled and unskilled labour, as between North and South. In countries where there is a relative shortage of the former and an abundance of the latter, rapid opening up of foreign trade will tend to induce specialization in activities using unskilled labour, to the detriment of those making intensive use of human capital, such as R\&D. Furthermore, as there is a lag in the spread of technological spillovers, the researchers of countries with a small knowledge base will find it difficult to compete with those of countries better endowed in this respect. The long-term growth rate of the first-named countries could be increased by giving them time to catch up with foreign technologies -and at the same time improve their capacity for imitation and innovationbefore exposing them to unrestricted international competition.

\footnotetext{
${ }^{16}$ It should not be assumed that the costs of such imitative R\&D are insignificant, however. Mansfield and others have estimated that the cost of copying a new product or process is equal to $65 \%$ of the cost of the original innovation (cited by Grossman and Helpman, 1991, p. 286).
} 
In short, endogenous growth models give rise to development processes in which it is admitted that there will not be convergence between the growth rates of North and South because the initial advantage of the Northern economies will tend to be further reproduced, resulting in an ongoing difference between their income levels and those of the South. This tendency can be partially offset if the efforts made by the latter make it possible to expand the international reach of the technological externalities generated in the North, if they are capable of taking the fullest advantage of their possibilities of imitation, and if they implement a form of trade openness which does not undermine the creation and full development of their domestic technological capacity.

\section{b) Public policies}

The neoclassical formulations on the functioning of competitive economies give rise to a generic recommendation that State intervention should be eliminated. ${ }^{17}$ The models we have just been discussing here, however, give rise to recommendations in favour of public intervention.

As noted by Grossman and Helpman (1994, p. 37), in economies that grow on the basis of innovation there are two types of obstacles that hinder attainment of the standards of efficiency usually associated with the free play of the market forces. On the one hand, the existence of monopolistic markets prevents the optimum condition of "equimarginality" whereby the prices of all the factors of production should be equal to the respective levels of marginal productivity. On the other hand, by not considering the effects of technological externalities, private agents obtain from their investments in technology -and, in more general terms, from their accumulation effortsreturns which are lower than the virtual social return of alternative decisions.

Both these obstacles give grounds for assuming that, in growth dynamics, it is possible to secure improvements in levels of well-being through State

\footnotetext{
${ }^{17}$ Indeed, the growth models claim that if individuals focus on distant horizons when defining their behaviour with regard to saving and take into account the future situation of their descendants, the long-term growth path of the economies will be socially efficient provided that the State does not intervene.
}

intervention. It is suggested that suitable public policies for this purpose may be of various types, depending on the origin and magnitude of the externalities and the nature and degree of imperfect competition. Clearly, however, emphasis is placed on intervention mechanisms which correct the rates of generation of technology to bring them closer to their socially optimal levels and which also disseminate the effects of the technological externalities and reduce the discretionality of monopolistic decisions regarding the qualities and quantities of the goods produced.

The new models have specific and particularly important repercussions on public policies typical of less-developed countries. Thus, for example, Romer (1993) holds that there is a technology gap between the less developed countries and the more highly developed nations. ${ }^{18}$ It may be concluded, from an analysis of the dynamics of that gap, that in the more backward countries public policies are of fundamental importance for the creation of the human capital needed in order to speed up growth. The State has a central role to play in building the necessary domestic base, by adapting the educational system and institutional frameworks to make the improvement of physical and human capital profitable for private enterprise.

As a general appraisal, it may be said that the new theories dealt with in this section treat technical progress as an endogenous factor in the growth process, while they consider such progress to be the result of explicit and conscious decisions to invest in technology.

The consequences of this change in attitude are to be seen in various areas. As we already saw, it is no longer reasonable to assume that there will be convergence between the growth rates of economies of different levels of development regardless of the circumstances. Nor is it valid to assert that the rapid and unrestricted opening of international trade will have beneficial and even-handed effects on all such economies, whatever their level of development. Finally, the new theories

\footnotetext{
18 In the study in question, Romer identifies two technology gaps separating the industrialized nations from the less developed countries: gaps in terms of "objects" and in terms of "ideas". The first of these refer to shortcomings in terms of physical and human capital, while the latter refer to access to the types of ideas which further the ongoing creation of new goods and processes in the developed countries.
} 
contain a clear justification of public policies, especially those having to do with the long-term development of backward economies.

It must be borne in mind, however, that this justification assumes that there will be continuing full use of production resources over time, which means that no account is taken of the possibility of various kinds of imbalances and fluctuations. As we shall see below (section IV), the models which are termed "evolutionary models" have features which permit them to overcome this highly restrictive assumption.

\section{IV}

\section{The "evolutionary" school}

\section{General features}

Like the neoclassical endogenous growth models, evolutionary models highlight the role of technical progress in economic growth. They differ from them, however, in the following aspects: i) generally speaking, they emphasize the importance of the institutional context in which technical progress is generated and disseminated and the role of demand in growth, combining Schumpeterian and Keynesian variables, and ii) in the case of simulation models, they assume decision-making processes based on conventional heuristics or rules (limited rationality) and allow for the incorporation of the sectoral diversity of demand and technical progress.

In the evolutionary school, two types of models may be identified. Both of them have their advantages and disadvantages and may be considered complementary to each other. On the one hand, there are aggregate models, in which the decision-making processes of firms are not specifically dealt with. Such models make possible simple analysis of the influence of certain structural variables on growth. Assuming the existence of an initial technology gap between North and South, aggregate models seek to determine in which cases the international dissemination of technology will give rise to processes of convergence or divergence.

On the other hand, there are simulation models in which the aggregate dynamics of the system are identified through "artificial worlds" (Lane, 1993). These consist of a varied set of agents endowed with certain attributes, a certain environment, and a dynamic which operates through selection and learning mechanisms. These simulation models are more theoretically exact, since they explicitly identify the links between (microeconomic) decision-making rules and (macroeconomic) growth paths. They also have great flexibility for the incorporation of technological diversity and the contexts of competition and behaviour at the microeconomic level. Their disadvantage is that the complexity of the interactions may in some cases obscure the roles played by each of the variables in the system. ${ }^{19}$ This complexity makes it advisable to use them in combination with simpler analytical models, such as aggregate evolutionary models.

\section{Aggregate evolutionary models}

As well as taking into account the incidence of technical progress on the productivity of resources, as in endogenist neoclassical models, aggregate evolutionary models also take account of its incidence on international competitiveness, which conditions the growth rate through effective demand. Thus, aggregate models assume that the long-term growth rate of a country will be that which is compatible with balance-of-payments equilibrium, which introduces a Keynesian component into the model, associated with the income elasticities of demand for exports and imports, corrected by the availability of international finance. ${ }^{20}$ These variables define the behaviour of demand on domestic and external markets.

\footnotetext{
19 This is, basically, the criticism that Romer makes of the simulation models. See, in this respect, his comments on the article by Dosi and Fabiani (1994), published together with that article.

20 See McCombie and Thirlwall (1994, chap. 3). The restrictions on demand are viewed in the context of an open economy and expressed as balance-of-payments constraints. This clearly coincides with some key issues dealt with in the early ECLAC ideas.
} 
There are various types of aggregate evolutionary models. ${ }^{21}$ Here, we shall refer to the model by Verspagen (1993), because of its ability to represent, in a simple manner, a broad range of convergence and divergence paths (see Appendix 2). Verspagen's model suggests that in the countries of the South, technical progress is, on the one hand, a non-linear function of the initial level of the technology gap. Up to a certain point, the existence of such a gap favours technical progress in the South, because it permits the imitation of existing technologies. If the gap is very large, however (greater than a certain critical value), the spread of technology becomes more difficult, because the capacity for imitation goes down with the distance behind the technological frontier.

For a given initial level of the gap, the intensity of imitation will depend on the existence of domestic learning capacity, that is to say, the existence of a domestic institutional base which makes it possible to identify, adapt and improve the technology to be imported. In the model in question, this base is expressed through the parameter $\delta .^{22}$ If the intrinsic learning capacity is very small, the international dissemination of technology will be only feeble.

The technology gap also implies a gap in terms of competitiveness between North and South. The lower competitiveness of the South is reflected in lower growth of demand and less incentive for growth. The global incidence on growth will depend

${ }^{21}$ Among them are those by Amable (1994), Canuto (1995) and Cimoli (1988). Each of these authors offers a model with some distinctive features that make them members of a single family tree whose main trunk is formed by aggregate models dealing with North-South technological dynamics.

22 In principle, this parameter will depend on factors that affect the capacity for the future absorption of technology or the capacity for learning over time but are not reflected in the initial technological level. Otherwise, they would already be taken into account in the initial level of the technology gap. In highly simplified terms, it could be held that two countries from the South with similar levels of factor productivity will have the same initial technology gap compared with the North. However, if one of them has, for example, a system of support for innovation or a credit programme to promote the dissemination of new technologies, it will be able to import or disseminate the technological advances made by the North more rapidly. The initial gap is the same, but the parameter $\delta$ is different, because the science and technology institutions are different. on the direction and intensity of the competitiveness effect and the technology dissemination effect.

Thus, the model in question plays down the optimistic idea, implicit in most of the models based on "catching up", that the technology gap leads automatically to the more rapid spread of technology. Convergence is conditioned by the existence of certain national institutional and technological capacities. Moreover, even if the size of the gap remains stable, this does not guarantee the convergence of growth rates if there is still a difference in the absolute levels of productivity (and hence of competitiveness). ${ }^{23}$ Convergence would be achieved only by speeding-up the autonomous innovation process in the South.

It should be noted that the model assigns an important role to public policies, which act by changing the parameter $\delta$. In this sense, Verspagen's model defines the field of action of public policies in broader terms than Romer's model, by incorporating the whole range of institutions that influence the technological learning process.

\section{Simulation models}

Simulation models make it possible to capture the diversity of the microeconomic agents and the sectoral diversity of technology and demand with a high degree of detail. The model by Dosi and Fabiani (1994) is an example which is relatively simple but illustrates the potential of this type of analytical construct for studying growth dynamics (see Appendix 3).

This model assumes the existence of two sectors, $m$ firms and $n$ countries. The decisionmaking units are the firms, which decide how much they will invest in innovation or imitation and what price they will charge for their products, using conventional rules of behaviour for this purpose. It is considered that these rules more adequately reflect the taking of decisions in conditions of uncertainty

\footnotetext{
${ }^{23}$ As may be seen in Appendix 2, the absolute equilibrium value of the gap $G$ (at which the rate of increase of the gap is zero) is positive, which means that the gap does not close completely. For this equilibrium value of $G$, the difference between the growth rates of the product in the North and in the South will have a constant positive value $(D>0)$.
} 
than the maximization rules, which would not be applicable to a context of limited rationality which depends precisely on those conditions. ${ }^{24}$

Technical progress generates increases in productivity in accordance with a stochastic process that depends on investments in technology and the technological opportunity of the sector. These increases in productivity alter firms' competitiveness ${ }^{25}$ and redefine their market shares. The dynamics of the system can give rise to virtuous circles of growth and competitiveness. Thus, as it is assumed that investment in technology is a percentage of the firm's sales in the previous period, expanding firms will also increase their investments in technology and will therefore have greater probabilities of innovating or imitating successfully in the following period.

The intensity with which stragglers are eliminated from the market (selection) or manage to imitate the new technologies (learning) depends on three classes of parameters: i) technological parameters, which determine how far the innovation effort changes the firms' productivity (technological opportunity) $)^{26}$ and the degree of difficulty of imitation (appropriability of the innovation); ${ }^{27}$ ii) parameters of behaviour, which define to what extent increases in productivity will be reflected in lower prices and/or greater competitiveness, through the application of a mark-up over costs, and iii) parameters relating to the market structure or competitive environment, which define the intensity of the selection process for a given difference in

24 With regard to the problems of finding regularities of behaviour in conditions of Knightian uncertainty, see Possas (1988).

${ }^{25}$ This occurs through changes in prices, assuming that these are fixed by applying a mark-up over costs.

26 The greater the technological opportunity, the greater the increases in productivity associated with successful innovation and, hence, the greater the impact of the innovation on competitiveness.

27 The greater the appropriability of an innovation, the slower its imitation. The appropriability depends on the accumulativity and tacit content of technical progress. Accumulativity exists when the probability that a firm will find an innovation in the period $t+1$ is a function of its distance from the technological frontier in period $t$ (for a given investment in R\&D). The tacit content of the innovation is the degree to which mastery of the technique depends on the amount of experience in production and the investment in technology, in contrast with learning through manuals or other coded forms of dissemination. competitiveness. ${ }^{28}$ As a function of these parameters, the model can give rise to a process of emulation -if the imitation process (learning by the stragglers) is faster than the selection process- or else to rapid concentration of the market, if the opposite is the case.

There are mechanisms which limit the intensity of the selection and the tendency towards market concentration, for given values of the parameters. The model in question envisages the possibility of adjustments in the exchange rate when the trade balance runs up large deficits. It also incorporates a wage adjustment mechanism whereby wages increase more rapidly when the level of employment rises. This means that countries that grow more quickly will have larger wage increases, thus favouring the competitiveness of the stragglers. At the same time, the random nature of technical progress means that past expansion does not automatically result in higher productivity in the future. The fact that innovation and imitation are stochastic processes opens up additional possibilities of change in industrial leadership, including processes in which the leader is overtaken by firms and countries that were stragglers ("forging ahead").

Different growth paths can be generated by changing the parameters (such as those regarding the characteristics of the technology, the competitive environment and the decision-making rules) or the initial conditions of the model (such as the number of firms and their characteristics, the type of sectoral specialization and the distribution of markets). This gives simulation models great flexibility for reproducing different economic development experiences. Such changes in the parameters and in the definition of the initial conditions should correspond with the available empirical information, of course.

This potential for interacting with results taken from economic history and from case studies is one of the main virtues of simulation models. As noted by Nelson (1994), traditional neoclassical theory reached a "ceiling" in the 1960s, partly because of its inability to absorb the wealth of information offered

\footnotetext{
${ }^{28}$ For example, markets with a large number of marginal firms will tend to have more intensive selection processes than those in which only a few large firms are competing with each other.
} 
by historical and empirical research. Evolutionary simulation models open up a doorway to the knowledge accumulated in other areas, which historians and economists can cross (in both directions). ${ }^{29}$

At the same time, simulation models offer a natural path for making aggregate growth models increasingly precise. This does not mean that such models should be replaced or abandoned, ${ }^{30}$ for the simplicity of aggregate models allows them to be used for the analysis of fundamental theoretical problems which could remain unsolved because of the complexity of simulation models. The latter, however, do make it possible to deal comprehensively with the non-linear aspects and imbalances which are inherent in complex systems such as economic systems.

Finally, simulation models are particularly appropriate for studying the effects of economic and industrial policies. The greater realism of their microeconomic assumptions and their great flexibility give them advantages in this field compared with aggregate models, whether conventional or evolutionary.

Evolutionary models have brought out both the importance of the role of development policies for inducing the sustained growth of lagging economies and the fact that the technological effort made by such economies is the key to international convergence or divergence. In the light of these models, the role of development policies is seen to be both broad and complex: they must stimulate the spread of technology, and not merely the attainment of higher rates of accumulation of physical capital, which is seen primarily as a vehicle for the learning process. The construction of institutions in the field of science and technology becomes important in view of the massive transfer of resources between sectors. This does not mean that the type of sectoral specialization is irrelevant. Any horizontal policy for stimulating the dissemination of technology has important sectoral consequences, since it favours some activities more than others and thus redefines the growth path. By giving priority to science and technology policy, the evolutionary models suggest that the desired structural change should be sought more through indirect dissemination methods than through direct subsidies for accumulation in certain sectors.

Indeed, an interesting line of future research would be to use simulation models to study the different growth paths that could be generated on the basis of various different sectoral structures and different assumptions regarding technology and demand in the initial period.

\section{V}

\section{The new ECLAC}

\section{ECLAC and the new growth theories}

Since the mid-1980s, ECLAC has been incorporating the results of the new growth theories mentioned above into its approaches. This permeability of ECLAC thinking is due, as already noted, to the fact that the core of its original contributions already contained concepts which have now reappeared and are being highlighted in these theories. Moreover, many empirical studies carried out in ECLAC and, above all, the efforts to renew their interpretation and the proposals put forward by that institution in the

\footnotetext{
29 Quite an obvious direction for the construction of new simulation models is a systematic analysis of sectoral diversity, which is given relatively little attention in the two-sector model by Dosi and Fabiani. Another direction is the incorporation of the specific features of labour markets in the North and the South. A differential aspect which is as yet under-analysed is the heterogeneity of those markets in the economies of the South, where underemployment (that is to say, employment at very low levels of productivity) affects a very high percentage of the total economically active population.
} 
1980s are basically consistent with evolutionary theories. ${ }^{31}$ It should also be borne in mind that the basic subject of ECLAC's studies -the Latin American economies- implies a recurrent challenge to conventional theories, both because of the special features of these economies and the problems which beset them in the 1980s.

The big changes taking place in the international setting (the technological revolution, globalization) call for the reinterpretation of the problems of Latin American development and the reformulation of proposals for overcoming them. The analyses made in recent years are not as consistent in content or form as those made by ECLAC in its first decades of activity, but this may be attributed at least in part to the level of complexity of the phenomena that must be dealt with now, or, if one prefers, to the depth and speed of the changes. To a certain extent, the efforts of the "new ECLAC" may be seen as an attempt to apply the more recent growth theories to the study of Latin America, with emphasis on the policy implications of those theories in the structural and institutional context of the countries of the region. As we shall see in due course, these implications are directly related to the importance assumed by technological dynamics, increasing yields and externalities in the new theories. ${ }^{32}$

\section{Competitiveness and growth}

The starting point for the arguments of the new ECLAC is the importance of competitiveness for sustained long-term growth. The "genuine" competitiveness of an economy is understood as "the capacity to increase (or at least maintain) its international market share while at the same time

\footnotetext{
${ }^{31}$ Indeed, in his study La industrialización trunca de América Latina Fajnzylber (1983) anticipates the general ideas of the new evolutionism. This and other later works by Fajnzylber are undoubtedly landmarks in this renovation. Among them, special mention may be made of "International competitiveness: agreed goal, hard task" published in CEPAL Review (Fajnzylber, 1988) and Industrialization in Latin America: from the "black box" to the "empty box" which appeared in the "Cuadernos de la CEPAL” series (Fajnzylber, 1990).

${ }^{32}$ Everything indicates that in the effort that culminated in the late 1980 s with the document "Changing production patterns with social equity" (ECLAC, 1990), the influence of evolutionary ideas was predominant. Since then, ideas from the endogenous growth theories (ECLAC, 1992, 1995 and 1996) have been gradually incorporated as these theories develop.
}

raising the standard of living of the population". ${ }^{33}$ This capacity depends on the incorporation of technological progress, as reflected in the ongoing introduction of new processes and the production of new goods and services. In the long term, in order to increase the competitiveness of an economy it is necessary to reduce the distance separating it from international best practices (or at least prevent this distance from increasing). At the microeconomic level, this means attaining the standards of efficiency prevailing in the rest of the world with regard to resource use and the quality of the products or services offered, which in turn implies the identification, imitation and adaptation of new production functions by enterprises (ECLAC, 1990).

With the intensification of international competition and the development of information technology, the incorporation of technical progress becomes a salient feature in the production of a wide range of goods and services. Consequently, in order to win a successful place in the world economy there must be ongoing efforts to improve the efficiency with which production resources are used, to incorporate intellectual added value into the goods and services produced, and to keep on raising the skills of the population so as to increase its capacity to participate in the processes of innovation and the dissemination of technology. These conditions are directly related with the type of production specialization followed by the region, which is related in turn with the behaviour of demand and technical progress in the different sectors of the economy (ECLAC, 1990).

\footnotetext{
${ }^{33}$ ECLAC, 1990, p. 68. Genuine competitiveness is seen to be different from the type of competitiveness deriving from short-term or "spurious" factors, such as an undervalued exchange rate or low wages. This definition is in line with the term "structural competitiveness" proposed by the Organization for Economic Cooperation and Development (OECD). Quite apart from its implications in terms of successful enterprise management, the latter term reflects the strength and efficiency of the national production structure, the long-term trends of the rate and structure of investment, the technical infrastructure, and other factors determining the externalities providing support for the activities of enterprises (OECD, 1992, p. 243). Likewise, both these definitions are similar to that used in the 1985 report of the Presidential Committee on the competitiveness of United States industry, according to which a nation's competitiveness reflects its capacity to respond to international market challenges, while at the same time increasing the real income of its citizens.
} 
As we have seen, the growth of trade in manufactures is greater than the growth of world trade as a whole, especially in the branches where technological innovation is most intense. ${ }^{34}$ This suggests that the only sustainable way of penetrating international markets is to add knowledge to the goods and services exported. It is also asserted that the polarization between primary commodities and industrial products has lost significance. Nowadays, the most important thing is to produce goods involving the intensive use of knowledge and technology, along with the creation of exportoriented production and services networks (ECLAC, 1990 , p. 84). In other words, rapid export-driven growth calls for the diversification of goods and markets in the direction of the most dynamic products, which are generally those with the greatest technological content and value added.

In the difficult transitional period of the 1990s, in spite of their limited demand elasticities exports based on the processing of natural resources may become a means of progressing to the export of manufactures of higher technological content, provided that they give rise to an "export mentality" which becomes firmly rooted in the systems of production, transport, marketing and finance (ECLAC, 1990). However, the key to long-term growth of productivity and the product lies in a successful effort to improve the export structure.

It is clear that this proposal is more than a mere hypothesis. Thus, ECLAC notes that "There is a distinct process at work which is establishing a new pattern of international specialization. As a result, the region's countries appear to be increasingly dedicated to highly standardized industrial products over whose international prices they have no decisive say, since these products are traded in highly

\footnotetext{
34 In the period 1962-1985, "the growth rate of exports of primary commodities $(1.6 \%)$ was less than that of naturalresource-based manufactures (mainly processed foodstuffs), which grew at the rate of $3.7 \%$. Traditional non-naturalresource-based manufactures, for their part (mainly labour-intensive consumer goods), grew at the rate of $6.8 \%$, while the highest growth rate, $8.1 \%$, was registered by the new manufactures heavily reliant on research and development (microelectronics, telematics, biotechnology, genetic engineering and new materials)." (ECLAC, 1990, p. 41).
}

competitive markets. From this standpoint, the productive system is adapting to a new set of relative prices that are closer to the opportunity cost or international price of the resources; at the same time, however, the main sectors of activity have become technologically less complex than during the import-substitution phase or have lost the capacity to stimulate technology assimilation processes in other sectors" (ECLAC, 1996, p. 39).

The foregoing considerations bring us to a central aspect of the arguments of the new ECLAC. In recent years, the economies of the region have passed through a rapid process of increasing external openness, which is seen as a positive factor from the point of view of competitiveness and in comparison with the inefficiencies associated with the indiscriminate protection applied in previous periods. At the same time, however, it is understood that, if used as an exclusive policy instrument, such openness can heighten the less dynamic type of specialization currently observed. In order for there to be a "virtuous" form of insertion in international trade, pro-active (mesoeconomic and microeconomic) policies are needed that will make it possible to correct the flaws in the technology and human capital markets, as well as in the oligopolistic markets for products subject to increasing returns. At the same time, if these increasing returns are associated in many sectors with economies outside the firm, the price mechanism will not be capable of adequately reflecting the social yield of the production and of the investments made in it (ECLAC, 1996). This is a further justification for adopting deliberate policies in the areas of trade, production and technology, or, in more general terms, development policies which promote changing production patterns in the economies of the region, with a view to the attainment of genuine competitiveness.

\section{Competitiveness and the national innovation system}

In this field, the new ECLAC shows significant advances, since it directly addresses the area of the interactions of public and private agents and their role in innovation and the dissemination of technology. ECLAC maintains that each country, region or enterprise has a specific context which causes the agents to react differently to a given signal. This context includes i) the technological 
opportunities and obstacles $;{ }^{35}$ ii) the experience and skills acquired by individuals and organizations; iii) the capabilities and experience that flow from one economic activity to another; iv) the institutional environment, determined by the combination of public and private mechanisms and institutions and the existence of major processes of "institutional innovation" (understood as the capacity to adapt and transform the institutional schemes on which the capacity for innovation is based), and v) conditions of mutual interaction between the creators of technological innovations and their users, which can be of crucial importance for either stimulating or inhibiting enterprises' capacity for learning and adaptation (ECLAC, 1990).

These conditions come under what is called the national innovation system, which is defined as the set of agents, institutions and rules of behaviour that determine the rate of importation, generation, adaptation and dissemination of technological knowledge in all the sectors of the economy, including human resources training activities and their financing (ECLAC, 1996). The characteristics of the national innovation system are determined by the degree of scientific and technological maturity, ${ }^{36}$ the system of macroeconomic incentives, the regulatory framework, and the business, legal and regulatory "culture".

The importance assigned to the national innovation system reflects the view that the consolidation and expansion of this system -or, if preferred, the increase in innovation capacity that this implies- is the key element in development policy and/or policies for changing production patterns.

\footnotetext{
35 As already noted (see footnote 26), the greater the technological opportunity, the greater will be the increase in competitiveness associated with a successful innovation. In turn, the technological opportunities are determined by the prevailing technological paradigm, so that the appearance of new paradigms leads to their reformulation, both as regards their scope and their ease of materialization. The sectoral distribution of such opportunities depends on the nature of the activities, the technological distance from the "revolutionary core", and the knowledge base (Dosi, 1988).

${ }^{36}$ The greater the maturity of the technology (standardization and slow rate of change), the less costly it is to transmit the relevant information over longer distances (both geographical and cultural). On the other hand, when the technology is changing rapidly and radically, geographical and cultural proximity is more important (ECLAC, 1990).
}

\section{The question of equity (technology, competitiveness and equity)}

The links between technology, competitiveness and equity occupy a particularly important place in the proposals of the new ECLAC. Lower wages are often perceived as a variable that favours competitiveness, but in the ideas of the new ECLAC the concept of competitiveness incorporates technical progress and also equity. Moreover, it is suggested that greater equity favours the spread of technology, since it gives rise to a more favourable framework for the efforts to further inter-firm cooperation required by the new technologies. At the same time, this includes elements of a virtuous circle, as increases in productivity would permit a gradual improvement in income distribution.

The relation between the domestic market and competitiveness also takes on new dimensions (ECLAC, 1990); it is perceived that expansion of the national and regional domestic market deriving from growth with equity provides an irreplaceable base for tecnological learning. The arguments in this respect note that in the cases where there has been feedback between competitiveness and equity the following phenomena have been observed: i) a change in agriculture towards more homogeneous agrarian structures, with rises in productivity; ii) more equitable access to property, through the creation of small and medium-sized enterprises tied into the production system and registering growing levels of productivity; iii) upgrading of labour skills, universal access to education and a higher degree of social integration; iv) growth in employment, linked with export growth; v) increases in productivity and wages; vi) the spread of an industrial rationale, and vii) income redistribution through the public finances.

As may be gathered from this, the new ECLAC holds that the expansion of the economies of Latin America depends on the attainment of genuine competitiveness, based on the ongoing generation and incorporation of technical progress, which are likewise necessary for sustaining an outward-looking growth pattern. In order to achieve this sustainability, production and technology policies of various types and scopes are needed, among which special mention may be made of those designed to consolidate and expand the national innovation system. It is also perceived that the success of these policies cannot be divorced from the gradual improvement of distributional equity, both because of its effects on 
the dimensions of the domestic market and its indirect effects on the growth of innovative capacity.

The brief summary given in the previous paragraph highlights the links between the new ECLAC proposals and the most recent endogenist and evolutionary models. Essentially, the analytical effort of the endogenist models is focussed on the treatment of technical progress as an endogenous variable. That effort is also aimed at outlining the policies required in order to avoid increasing divergence or even to achieve a process of international convergence.

\section{VI}

\section{Comparison of the most recent growth models with the ECLAC approach}

In the previous pages, we described some recently formulated growth models which are also useful for the analysis of North-South relations and we outlined some approaches to these matters developed in Latin America, especially in ECLAC and its academic circles. In this section, we will review and compare some key aspects of these approaches and those models.

The first item that strikes us is the importance assigned by the most recent growth models to technological knowledge as an economic growth factor and their general agreement on the important role of the technical progress of each country as the main source of international differences, reflected in the divergences between long-term growth rates. The new models thus bring up once again an aspect which was of central importance in the conception of the centre-periphery system formulated by ECLAC in its early years, which attributed the bipolar nature of economic development to the slow and uneven spread of technical progress through the international economy.

It should be borne in mind that in the late 1940s there were no theoretical schemes permitting a systematic analysis of the links between technology and growth. These links were only incorporated into formal economic models after a long and complex process which only began to show marked advances as from the mid-1980s. Since then, substantial differences have begun to be observed in the conception of technical change.

Whereas the original ECLAC approach may be interpreted as being connected with what we now call the "metal products and machinery-based technological paradigm", both the new theories and the recent documents of ECLAC have arisen in a period of "technological revolution" in which a new paradigm is assuming increasing prominence: that based on information technology. Under the previous paradigm, technology was seen mainly as being incorporated in capital goods and was reflected in changes in processes and products and, ultimately, in particular sectors of activity. Similarly, technical progress was seen as being exogenous to production activities and enterprises, as well as to the economic systems of the periphery.

The extraordinary speeding-up of technical change in the last fifteen years and the great capacity for the spread of information technology to an ever-growing range of goods and services have formed a context in which the technology factor can hardly continue to be viewed as exogenous. This, together with the evolution of the theories themselves, has formed the basis for a profound change in the manner of visualizing technical progress.

In the neoclassical tradition, emphasis is now placed on technology's character of a non-pure public good. Innovations are generated by enterprises in a system of monopolistic competition which permits the partial appropriation of their benefits by those enterprises. At the same time, the technical progress that they do not appropriate generates technological externalities which become a key element for explaining economic growth.

In the evolutionary approach, emphasis is placed on the tacit and accumulative nature of technological knowledge, which makes the processes of generation, imitation, adaptation and dissemination more complex, a fundamental factor being the surrounding institutional environment. Technical 
progress determines the competitiveness of products, enterprises and economies, conditioning the long-term growth rate through the demand for the various goods, in an increasingly interdependent world. This explains both the sectoral technological diversity and the international differences in per capita income growth rates.

The ECLAC of the 1990s basically has a systemic conception of technical progress. Indeed, the development of a national innovation system forms one of the central proposals of ECLAC neostructuralism ${ }^{37}$ and represents the hub of technological and production policies because of its influence on the development of local learning capability. This base of a markedly evolutionary nature is accompanied by arguments deriving from endogenous growth theories: the technology market has flaws due to the fact that technical knowledge and information is a non-pure public good, and these flaws lead to under-investment in technological matters and justify direct State intervention through mesoeconomic or "horizontal" policies.

A second aspect which needs to be compared is that of the attitudes to sectoral development policies (also known as "horizontal" policies). These attitudes derive from the different conceptions of technology. In the traditional ECLAC approach the sectors were clearly defined. It was considered that industrial development should be supported, especially in the case of those activities where the productivity of capital was closer to that of the centres, by establishing a system of protective tariffs, with decreasing levels of protection, to make up for the disadvantages inherited from the past. It was also considered that, in order to offset the tendency to an external imbalance inherent in the industrialization of peripheral-type economies, it was necessary to undertake the production of goods at different stages in the industrial chain. ${ }^{38}$ Likewise, in view of the requirements of some of these goods in terms of production scales, it was also considered that the industrialization effort should be carried out in economic spaces of a suitable size, which could be achieved more easily through regional integration.

\footnotetext{
${ }^{37}$ Making it different from other proposed processes of change for the region, such as those of the World Bank.

38 Simple consumer goods, complex consumer goods, intermediate inputs, widely used intermediate inputs, and capital goods.
}

In the new models and approaches, the above sectoral approach has become less clearly defined. It is not that production specialization has lost importance -there is a general view that greater international division of labour is a positive factor for trade- but there is general agreement on the growing difficulty of picking "winners" and "losers" in advance at a time of intensive changes in technologies and markets. ${ }^{39}$ Although it is acknowledged that technical progress may be concentrated in specific areas or branches of science and technology, there is no clear advance knowledge of the sectors of production which are going to expand most because they are "technology vectors" or make intensive use of knowledge. Thus, for example, while giving priority to science and technology policy, the evolutionary models suggest that the desirable structural changes should be sought mainly through indirect (or horizontal) means rather than through massive transfers of resources between sectors.

Much of the difficulty of forecasting "winning" sectors is undoubtedly connected with the fact that the new technologies make intensive use of knowledge, but the latter is highly dynamic. The Latin American debate on development policies is also influenced, however, by some attitudes which are closer to the ideas of unbridled liberalization than to the analytical bases of the new growth theories. These attitudes range from negation of the sectoral perspective and even of industrial development policy itself to an extreme position which questions both the deliberate promotion of industrialization (which ECLAC advocated up to the late 1980s) and the industrialization in closed markets which was actually taking place and whose inefficiency is rather unfairly blamed on ECLAC. The implicit assumption of these attitudes is of course that the market optimizes resource allocation without any need for State intervention to guide and stimulate economic development, even in the case of the peripheral countries.

\footnotetext{
${ }^{39}$ Krugman (1992b) might be an exception in this respect. In the search for criteria on which to base a selective sectoral policy, and in the light of the concepts of pecuniary external savings and strategic complementarities, he proposes that geographical clusters of enterprises should be identified, that their causes should be investigated, and that an evaluation should be made of whether the externalities are substantial enough to warrant government support.
} 
In short, although the models and approaches analysed agree on the desirability of public policies to further the incorporation of technology and promote growth with a view to fostering international convergence, there has been a significant change in the method proposed: instead of the traditional policies of supporting specific sectors of production, it is now proposed that there should be policies to correct, complete or promote factor markets -especially those for human capital (educational policies) and technology (science, technology and innovation policies) - as well as to address other institutional aspects that determine the environment in which enterprises operate.

The third point of comparison which is worthy of note concerns the concepts of bipolarity and of the international divergence of long-term per capita income growth rates. The endogenist models recognize the possibility that the initial advantage of the economies of the North tends to be reproduced, resulting in an ongoing difference between their income levels and those of the countries of the South. This tendency could be checked if the efforts of the latter were concentrated on absorbing the technological externalities generated in the North and taking the fullest possible advantage of the possibilities for imitation, by adopting a form of trade openness which is compatible with the creation and maturity of their domestic technological capabilities.

The evolutionary models, for their part, represent a wide range of possible growth paths, although those that take into account conditions of backwardness typical of less developed economies give results that indicate a widening of the income gap. The convergence paths are conditional upon the existence of national institutional and technological capacities. The truth is that if there is to be progress towards comparable levels of per capita product among countries it is indispensable that the autonomous innovation process in the South should be speeded up.

In the first stage of ECLAC's analytical studies, bipolarity was the main analytical way of expressing the problems of the periphery, which was seen as an anomaly in comparison with a paradigm of smooth and harmonious functioning of the international economy on the basis of a division of labour providing for the joint industrialization of both poles of the system. The concept of bipolarity means that the spontaneous relations between the two poles are not such as to generate this joint industrialization but in- stead perpetuate the structural differences: heterogeneity and specialization of the periphery, on the one hand, and homogeneity and diversification of the centres on the other. This differentiation is the underlying element in the unequal evolution of the levels of per capita product.

At the time, bipolarity emerged as an alternative concept to that of static comparative advantages, which advocated the optimization of international resource allocation through unrestricted free trade. In terms of the modern debate on convergence, the initial ECLAC attitude stressed that if the periphery did not industrialize -in other words, if it did not incorporate technical progress- there would be international divergence of income levels between one pole and the other. As already noted, subsequently emphasis was also placed on the need -likewise subject to economistic criteria- to develop those branches where peripheral industrialization could not make a start because of its initial specialization: consumer durables, widely-used inputs, and above all capital goods.

The ECLAC approach in the 1990s is the opposite to that which claims that liberalization itself automatically produces convergence. Although there is no clear reformulation of the bipolarity hypothesis in its recent documents, the present ECLAC attitude could be classed with that termed "conditional convergence". It suggests that the gradual reduction of differences in income between the countries of the region and the developed countries, with parallel absorption of the increase in the economically active population, would be obtained by attaining a given rate of growth of per capita income, which in turn means a certain rate of increase of the product and a high investment coefficient. ${ }^{40}$ In order to realize this possibility of convergence it is necessary to adopt a set of policies focussed on the construction and development of a national innovation system.

\footnotetext{
40 "Rapid and sustained growth for the Latin American and Caribbean countries, which will represent a gradual decrease in income disparities in relation to the developed countries, will clearly improve the region's traditional performance. Absorbing the increase in the active population will mean a systematic rise in real per capita incomes at a rate of $4 \%$ per annum, with relatively minor fluctuations from one year to the next. In order to achieve these goals, the countries must expand their gross domestic product at rates of nearly $6 \%$ per year. ..... such a performance will require an investment of around $28 \%$ of regional GDP, which means a 7\% increase in the current average ratio ...." (ECLAC, 1996, p. 51).
} 


\section{VII}

\section{Final remarks}

The foregoing review of some of the main recent growth models, and their comparison with the views of ECLAC, was designed to bring out their analytical similarities or divergences and to identify the different theoretical bases on which they were constructed. Prime emphasis was placed on the convergence of their views on the role of technical progress as the main source of the differences between countries, as reflected in the divergences between their long-term growth rates.

This review also revealed another type of convergence which is worth noting in these final remarks: in the light of all the models and approaches reviewed, it is clear that there is significantly more scope for the application of policies to promote growth. It was not possible, however, to analyse in depth the various theoretical grounds justifying State intervention.

In the endogenous growth models, this greater scope stems from the consideration of new "market flaws" connected with monopoly situations (necessary in order to provide incentives for investment in innovation) and with various types of externalities (necessary for the long-term continuity of economic growth). Both the monopoly situations and the externalities generate non-optimal Paretian equilibria. Development policies could aim to correct these flaws, resulting in higher growth rates. The existence of such flaws is not new, but what is new is the recognition of their importance for long-term economic performance.

The evolutionary models, for their part, by incorporating institutional aspects, bring out the fact that the new public policies are necessarily more complex than in the past, so that veritable "institutional engineering" is needed to provide the coordination mechanisms that are missing in a free market economy. Development policy becomes a means of creating conditions of competitiveness in the economic system by coordinating the institutions with the strategies followed by enterprises in order to promote technological learning. In turn, this coordination must incorporate more general measures to ensure an efficient infrastructure, adequate scientific and technological resources, human resources training, and other aspects.

Thus, the new models reduce the validity of the arguments that largely blame government intervention for the relative failures of certain countries in terms of growth and participation in the international economy. However, they do not appear to incorporate in their bases, at least explicitly, two aspects which are typical of economies that, like those of Latin America, suffer from certain types of backwardness: on the one hand, backwardness in the diversification and linking-up of their structures of production, where there is little development of the technologically most complex activities, and on the other, backwardness in their existing levels of accumulation, which are indispensable for investment and economic growth. These disadvantages take on even more serious dimensions in a globalized economy where States have less and less independence in the management of their economic policies.

An aspect which will probably continue to occupy a leading place among policy concerns is the level of employment, which appears as a mere "residual" in the models studied: the greater the absorption of technical progress and the degree of capital accumulation, the smaller this residual value. Such an attitude is undoubtedly over-optimistic, however, in the case of economies like those of Latin America which display high degrees of structural heterogeneity: i.e., they still have significant contingents of workers employed in low-productivity activities.

Furthermore, in the 1990s many of these economies are in the midst of intensive restructuring processes. The transition between different production structures can give rise, even when it is taking place in the direction that is most desirable in the long term, to long periods of high unemployment, which not only has social costs but also involves a significant loss of growth potential of the product. It is therefore necessary to make a greater effort to construct models that take account of this specific aspect of the Latin American economies and make a more realistic evaluation of the impact of development policies on employment levels.

(Original: Spanish) 
APPENDIX 1

\section{Romer's model}

The model by Romer (1990) recognizes four production factors: i) technology (A), defined as a stock of knowledge, assimilable in turn to the quantity of designs of capital goods available; ii) capital $(K)$, equivalent to the sum of a set of production goods which are differentiated and hence not perfectly interchangeable; iii) labour $(L)$, made up of unskilled labour, the supply of which is assumed to be constant, and iv) human capital $(H)$, resulting from the cumulative effect of activities such as formal education and on-the-job training. The total amount of human capital is used in the production of a final good $\left(H_{Y}\right)$ and in research $\left(H_{A}\right): H=H_{Y}+H_{A}$. It is assumed that the stock of human capital remains constant.

These inputs are used in three sectors: i) the research sector, which produces new knowledge (for example, designs for new capital goods) on the basis of human capital $\left(H_{A}\right)$ and the existing stock of knowledge $(A)$; ii) the capital goods sector, which uses the designs developed in the research sector to manufacture the capital goods to be used in the final goods sector, and iii) the final goods sector, which uses labour $(L)$, human capital $\left(H_{Y}\right)$ and the differentiated capital goods to generate the final product.

The research sector operates in the following manner: if a researcher $j$ has a certain quantity of human capital $H_{j}$ and has access to a portion $A_{j}$ of the total stock of knowledge incorporated in previous designs, his output of new designs will be $\delta . H_{j} \cdot A_{j}$ (where $\delta$ is a productivity parameter common to all researchers).

The model assumes that all those carrying out research have free access to the total stock of knowledge. This is the same as assuming that knowledge is a non-rival good and, ultimately, that all researchers can make use of $A$ at the same time. The output of researcher $j$ will therefore not be the amount shown in the previous paragraph, but will instead be $\delta . H_{j} \cdot A$. Adding together the output of all the researchers, we obtain the following equation:

$$
\ddot{\mathrm{A}}=\delta . H_{A} \cdot A
$$

In this expression it is implicitly assumed that every additional unit of human capital included in the research increases the growth rate of technology, and not just its level. Every new design is added to the existing stock of knowledge, and furthermore this stock is never depleted. Consequently, the marginal product of the researchers grows in line with the growth of $A$. In other words, a researcher working at the present time and having the same human capital as another researcher a century ago (measured in terms of years of education) will have higher productivity than his predecessor because he will be able to take advantage of all the new knowledge accumulated over that period.

It is understood that this externality, which is a specific feature of the generation of knowledge, is produced not only over time but also between contemporary agents. In other words, it is at once inter-temporal and inter-agents. If the marginal product of $H_{A}$ were decreasing in line with the accumulation of designs, the lack of opportunities in the research sector would eventually cause the human capital to be used in the final goods sector, thus reducing the output of technology.

The sector producing capital goods cannot be characterized by a single representative enterprise because it is assumed that there is a different enterprise for each durable good $i$. Each enterprise acquires the design of capital good $i$ in the research sector and obtains a patent of unlimited duration. The owner of the design has exclusive property rights over it for the production of capital goods, but not for its use in research, so that designs may be characterized not only as non-rival goods but also as partially exclusible goods.

The total quantity of capital goods $(K)$ may be written as follows:

$$
K=\sum_{i=1}^{A} \cdot x_{i}
$$

where $x_{i}$ is the quantity available of capital good $i(1 \leq i \leq A)$.

In this sector there are increasing returns in the production of machinery and equipment because of the non-rival nature of the design, for the use of a design in the production of capital goods has a marginal cost close to zero. Because of this, the capital goods market has a monopolistic structure.

Capital goods are produced with the same technology as consumer goods, using the resources not used for consumption $(C): \Delta K=Y-C$.

The production function for non-differentiated final goods is written as follows:

$$
Y=H_{Y}^{\alpha} \cdot L^{\beta} \cdot \Sigma_{i=1}^{A} x_{i}^{l-\alpha-\beta}
$$


This function is assumed to be first-degree homogeneous, and it is also accepted that the product of this sector can be described in terms of the activities of a single price-taking representative enterprise. It is observed that the level of production of the final goods will depend not only on the quantity of labour and human capital but also on the level and diversity of the goods making up the capital aggregate.

The competitive nature and efficiency of the markets in the final goods sector will mean that $x_{1}=\ldots=x_{A}=x$, so that $\sum_{i=1}^{A} x_{i}=A \cdot x=K$.

Consequently, equation (3) can be written:

$$
Y=H_{Y}^{\alpha} \cdot L^{\beta} \cdot A \cdot x^{1-\alpha-\beta}
$$

which is transformed into:

$$
Y=\left(A \cdot H_{Y}\right)^{\alpha} \cdot(A \cdot L)^{\beta} \cdot(A \cdot x)^{l-\alpha \cdot \beta}
$$

Equation (3") reveals, through the explicit introduction of the non-rival input $A$, the mechanism whereby technical progress affects the volume of production. Thus, it is observed that an increase in the stock of capital goods (an increase in $K$ ) will have different results on the volume of production, depending on whether that increase merely consists of the use of more existing machines (an increase in $x$ ) or whether it involves the creation of new types of machines (an increase in $A$ ). In the latter case, the effect will be greater because in addition to the increase in the stock of capital there will be the effect of the technical progress incorporated in the new machines, reflected in the improvement in the efficiency of human capital and labour. $^{41}$

The model in question defines an equilibrium growth rate whose level depends crucially on the allocation of human capital between research and production activities and on the allocation of the final product between consumption and investment.

This growth rate is determined by the expression:

$$
g=\delta \cdot H_{A}=\frac{\delta \cdot H-\Lambda \rho}{\Lambda \cdot \sigma+1}
$$

In this expression $\Lambda=\alpha /(1-\alpha-\beta)(\alpha+\beta)$ and the intertemporal optimization condition of a consumer with an infinite horizon (along the lines of Ramsey's model) ${ }^{42}$ is defined as $\Delta C / C=(\mathrm{r}-\rho) / \sigma$, where $\rho$ is the intertemporal preference rate, $\mathrm{r}$ is the interest rate and $1 / \sigma$ (considered to be constant) is the intertemporal substitution elasticity between the amounts of consumption at different times. Through this ratio, consumer preferences thus have an influence on the growth rates of the model.

It may be noted that the greater the stock of human capital, the higher these growth rates will be. This is therefore the variable whose scale is most significant in the model, since it is the key input in the research sector. It may be inferred from this that the size of an economy is of particular importance, since it is the total amount of human capital (and not just its average level) which is the virtual determinant of its growth rate.

${ }^{41}$ This is reflected in increasing returns to scale which are not internalized by any individual producer of final goods. They are returns which are perceived at the aggregate level of all producers, since they derive from externalities which exist in the economy.
42 It may be recalled that Ramsey (1928) introduced into a neoclassical model the assumption that families select their consumption path through the maximization of a utility function subject to a budgetary restriction: that is to say, they adopt an optimal form of behaviour. 
APPENDIX 2

\section{Verspagen's model}

Verspagen's model assumes that technology acts on economic growth both directly and indirectly (Verspagen, 1993, p. 127). The direct effect is associated with the increase in the technological knowledge base that can be used by firms. The indirect effect is associated with the increase in exports, seen as a substitute variable for the increase in demand. Formally:

$$
y_{i}=\alpha \cdot t_{i}+\varepsilon \cdot x_{i} \quad i=s, n
$$

where $y_{i}$ is the proportional rate of growth of the product, $t_{i}$ is the rate of increase of technological capabilities and $x_{i}$ is the growth rate of the exports of country $i$. Equation (1) shows that the growth rate of country $i$ (in this case, $i$ can be a country of the North or of the South) will be a function of the rate of technical change and of export growth.

The export growth rate of each country is a function of its relative technological level -which reflects its international competitiveness, as expressed in equations (2) and (3)- and of the growth rate of the world economy, $z$.

$$
\begin{aligned}
& x_{s}=\eta \cdot L\left(T / T_{n}\right)+z \\
& x_{n}=\eta \cdot L\left(T_{n} / T_{s}\right)+z
\end{aligned}
$$

If $T_{n}>T_{s}$, then $L\left(T_{n} / T_{s}\right)=G$ (the technology gap) will be a positive number, which means that the exports of the North will grow faster than the international economy.

The rate of technical progress in the North, $t_{n}$, is a function of its autonomous rate of innovation $\left(\beta_{n}\right)$ and of its technological learning associated with learning by doing, which broadly reflects the "Verdoorn effect", represented by the term $\lambda . y_{n}$ in equation (4):

$$
t_{n}=\beta_{n}+\lambda \cdot y_{n}
$$

Obviously, the Verdoorn effect introduces positive dynamic impulses (a virtuous circle) into the system, to the benefit of the country which grows more quickly.

The distinctive aspect of Verspagen's model is the form of the function for technical progress in the South $-t_{s}$, in equation (5)- where the term $a . G . e^{-G / \delta}$ expresses the international dissemination of technology and $G=L\left(T_{n} / T_{s}\right)$ is the technology gap.

$$
t_{s}=\beta_{s}+\lambda \cdot y_{s}+a \cdot G \cdot e^{-G / \delta}
$$

Equation (5) indicates a non-linear relation between the gap $G$ and the rate of technical progress in the South, $t_{s}$, given by the term $G \cdot e^{-G / \delta 43}$ Up to a certain point, the technology gap stimulates the international dissemination of technology, because of the possibilities of imitation open to the more backward countries. This stimulus depends not only on the level of the gap but also on the parameter $\delta$, which represents a measure of the "intrinsic learning capacity" of the South. The maximum rate of dissemination of technology to the South is obtained when $G=\delta$. After that critical value is reached, dissemination weakens as the gap widens.

The higher the value of $\delta$, the greater the international spread of technical progress, for a given value of the gap $G .{ }^{44}$ The learning capacity of the South $(\delta)$ is associated with its production structure and science and technology institutions.

The movement of the gap over time is obtained by the subtraction of equations (4) and (5):

$$
d G / d t=t_{n}-t_{s}=\left(\beta_{n}-\beta_{s}+2 \cdot \varepsilon \cdot \eta \cdot \lambda \cdot G-a \cdot G \cdot e^{-G / \delta}\right) /(1-\alpha \cdot \lambda)
$$

43 The effects of autonomous innovation and the learningby-doing mechanism in the South are in no way different from those observed in the North. It is assumed that $b_{n}-b_{s}>0$, i.e., that the rate of autonomous innovation in the North is higher than in the South.

\footnotetext{
${ }^{44}$ When $\delta$ tends towards infinity, the international dissemination of technology becomes a linear function of the gap, which is the assumption implicit in the linear "catching-up" models. See, for example, Fagerberg (1988).
} 
FIGURE 1

Dynamics of the technology gap

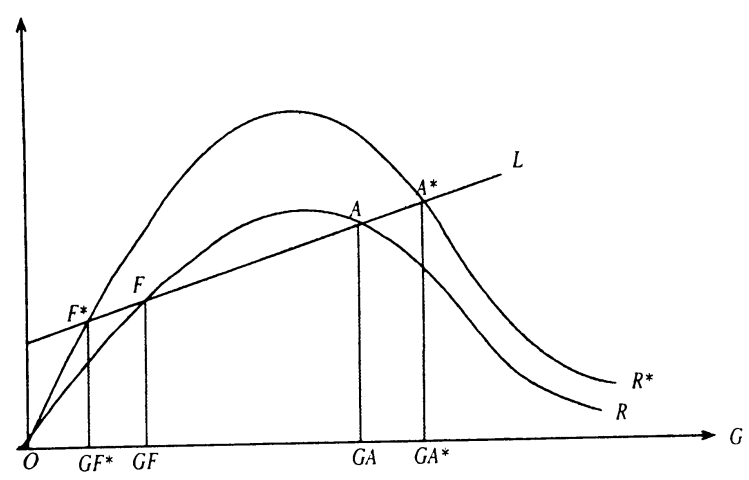

FIGURE 2

Dynamics of the gap and growth

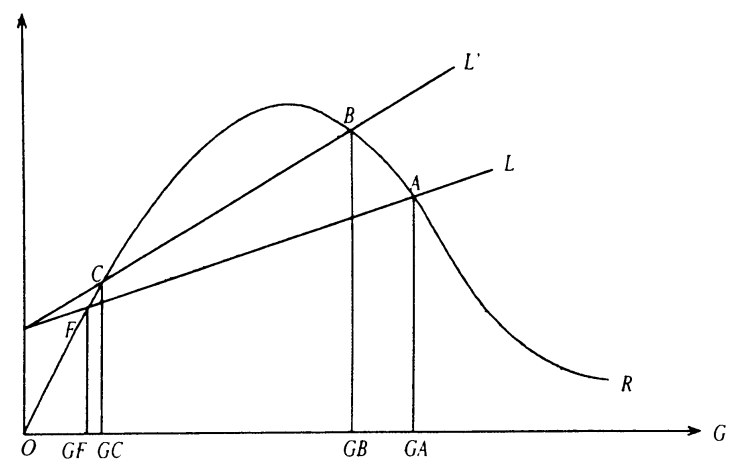

Equation $(6)$ shows that the gap closes $(d G / d t<0)$ when the international dissemination of technology exceeds the divergence effect produced by the autonomous innovation differential and the Verdoorn effect. ${ }^{45}$ The evolution of the gap over time is described in figure 1 , where the straight line $L$ represents the first two terms of the numerator in the equation $\left(\beta_{n}-\beta_{s}+2 . \varepsilon . \eta . \lambda . G\right)$, while the curve $R$ represents the last term $\left(a . G . e^{-G / \delta}\right)$, so that:

$$
d G / d t=(L-R) /(1-\alpha \cdot \lambda)
$$

For values of the gap between $G A$ and $G F$, there will be technological convergence, since the growth rate of the gap over time becomes negative. For values of $G$ greater than $G A$ or less than $G F$, there will be technological divergence. It may be noted that $A$ represents an unstable equilibrium point, whereas $F$ represents a stable equilibrium. Although the gap never closes completely (unless $\beta_{n}-\beta_{s}=0$ ), point $F$ represents the constant minimum value of the steady-state gap.

The position of point $F$ may be changed by changing parameter $\delta$, which is subject, as noted earlier, to the influence of industrial and technological policy. If the value of $\delta$ is increased, the curve for the international dissemination of technology $R$ moves up (generating curve $R^{*}$ ) and the stable-state equilibrium is obtained for a lower value of the technology gap, $G^{*} F^{*}<G F$. This is how policies designed to increase the capacity for the absorption of technology in the South bring about a change in the equilibrium value of the gap.

Finally, the convergence or divergence of growth rates is obtained by replacing the terms in (1):

$$
y_{n}-y_{s}=D=\left[\alpha \cdot\left(b_{n}-b_{s}\right)+2 \cdot \varepsilon \cdot \eta \cdot G-\alpha \cdot a \cdot G \cdot e^{-G / \delta}\right] /(1-\alpha \cdot \lambda)
$$

The effect of the gap on the difference between the growth rates of North and South $\left(D=y_{n}-y_{s}\right)$ includes a competitiveness effect and a dissemination-of-technology effect, as described in equation (7). The greater the gap, the greater will be the competitive advantage of the North, thus increasing the differential between the growth rates. This effect is partly offset by the dissemination of technology, which increases growth in the South. The net effect of the gap will be given by the difference between the above two effects, i.e., by the sign of the difference $\left[\alpha \cdot\left(\beta_{n}-\beta_{s}\right)+2 . \varepsilon \cdot \eta \cdot G\right]-\alpha \cdot a \cdot G \cdot e^{-G / \delta}$.

Figure 2 summarizes the effects of the technology gap and autonomous innovation rates on the evolution over time of the gap and of growth rates in North and South, for a given value of the parameter $\delta$. If we multiply both terms of the equation by $1 / \alpha$ we obtain the straight line $L^{\prime}=\beta_{n}-\beta_{s}+(2 . \varepsilon . \eta$. $G) / \alpha$, while $R$ continues to be the same curve as in figure 1.

Thus, we have:

$$
D=\left(L^{\prime}-R\right) / \alpha .(1-\alpha . \lambda)
$$

${ }^{45}$ Formally, technological convergence requires that $\beta_{n}-\beta_{s}+$

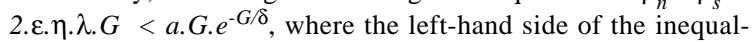
ity represents the effect of the autonomous innovation rates and the "Verdoorn effect" and the right-hand side represents the international dissemination of technology. 
Thus:

(i) for $G>G A$, both $D$ and $G$ increase steadily (growing divergence in terms of growth and technological capacity);

(ii) for $G B<G<G A$, there will be divergence in growth rates but technological convergence;

(iii) for $G C<G<G B$, there will be simultaneous technological convergence and convergence of growth rates;

(iv) for $G F<G<G C$, there will be technological convergence but divergence in growth rates, and

(v) for $G<G F$ there will be divergence in $D$ and $G$.

When the gap reaches its stable equilibrium at $F($ where $d G / d t=0)$ there will continue to be a positive differential in the growth rates of North and South $(D>0)$. The model permits a transitional dynamic, however, in which $D<0$ (a situation of emulation), which corresponds to the situation indicated in sub-paragraph (iii) above. In this case, the positive effects of the dissemination of technology on the rate of technical change in the South exceed the effects of the greater competitiveness of the North on exports and growth (these latter effects being determined by the existence of a differential, in absolute terms, between the respective technological capacities). Thus, the model suggests that there may be convergence during certain periods (transitional dynamic) but does not envisage the elimination of the difference in growth rates between North and South. ${ }^{46}$

\footnotetext{
46 If it were assumed that there is no link between exports and growth (formally, $\varepsilon=0$ ), then growth would depend solely on the direct effect of technology. This would be the case in an economy with permanent full employment, in which growth increases in line with increases in productivity, without changes in demand (through competitiveness) giving rise to any differ-
}

ences in growth rates between countries. The straight lines $L$ and $L^{\prime}$ become horizontal and coincide perfectly with each other, meaning that the technological convergence automatically induces convergence in growth rates. At the steady equilibrium point, both $d G / d t$ and $D$ will be equal to zero. 
APPENDIX 3

\section{The simulation model of Dosi and Fabiani}

The starting point for this model is provided by the firm's decisions on how much it wishes to invest in research and development (R\&D). These are defined on the basis of a simple rule: a percentage of total sales in the preceding period. Formally:

$$
R \& D_{i j}(t)=a_{1 i j} Y_{i j}(t-1)
$$

where $\mathrm{R} \& \mathrm{D}$ is the investment in innovation or imitation in the period $t, a_{i j}$ is a parameter reflecting the decision-making rule, and $Y_{i j}(t-1)$ is the total sales of firm $i$ of country $j$ in period $(t-1) .^{47}$

Through a two-stage stochastic process, ${ }^{48}$ the R\&D efforts give rise to increases in productivity associated with the discovery of an innovation or the successful imitation of competitors. Thus, the technological dynamic defines the evolution of the productivity of each firm, designated as $\pi_{i j}(t)$.

Price formation follows the rule of the application of a mark-up over costs:

$$
P_{i j}(t)=\left[w_{j}(t) / \pi_{i j}(t)\right] \cdot\left(1+a_{2 i j}\right)
$$

where $w_{j}(t)$ is the level of wages in country $j$ and $a_{2 i j}$ is a parameter which reflects the mark-up behaviour. The model has only one production factor: labour.

Competitiveness is defined as a function of the exchange rate and prices. ${ }^{49}$

$$
E_{i j}(t)=\rho_{j}(t) / P_{i j}(t)
$$

where $E_{i j}(t)$ is the competitiveness of firm $i$ of country $j$, and $\rho_{j}$ is the exchange rate of country $j$. Competitiveness governs the evolution of the firm's share in the domestic and foreign markets, in line with the following equations:

$$
\begin{gathered}
\Delta f_{i j}^{k}(t, t+1)=a_{3 j}\left[E_{i j}(t) / E M^{k}(t)-1\right] \cdot f_{i j}^{k}(t) \\
E M^{k}(t)=\Sigma_{i} \Sigma_{j} f_{i j}^{k}(t) \cdot E_{i j}(t)
\end{gathered}
$$

where $f_{i j}^{k}$ is the share in market $k$ of firm $i$ of country $j, E_{i j}$ is the competitiveness of firm $i$, and $E M^{k}$ is the average competitiveness in market $k^{50}$ Thus, $k$ represents the different national markets. Obviously, if $k$ is not the same as $j$, it will represent an external market for the firms of country $j$.

47 The model assumes that decisions on technological innovation and imitation are the result of "routine" behaviour: that is to say, they are based on fixed rules and are independent of other events. The authors say that although this rather an extreme assumption, there are good empirical and theoretical reasons for expecting inertial forms of behaviour in uncertain and changing contexts.

48 The probability of obtaining an innovation in period $t$ is defined as $\operatorname{Pr}\left\{I_{i j}(t)=1\right\}=1-\exp \left\{-\phi \cdot \operatorname{In}_{i j}(t)\right\}$, where $I n_{i j}$ is the number of researchers of firm $i$ of country $j$ seeking innovations, $I_{i j}$ is a binary variable which can have the values 0 or 1 , and $\phi$ is a parameter which depends on the technological opportunities of the sector. Higher values of $\phi$ indicate greater facility for finding new products or processes because of the number of researchers. In a second stage, if the innovation effort $\left\{I_{i j}(t)=1\right\}$ is successful, the increase in productivity deriving from this is the result of a Poisson distribution with a mean of $\lambda$, where $\lambda$ also depends on the technological opportunities of the sector (for example, $\lambda$ could be expected to be higher in the informatics sector than in the textile sector). Simi- lar equations are formulated for the imitation process. In this case, the probability of successful imitation will be a function of the number of researchers assigned to the search for imitations and of a parameter $\chi$ which reflects the difficulty of imitation in that specific sector. This parameter depends on certain characteristics of the technology, such as the extent to which know-how can be disseminated through manuals, the role of experience, patents and industrial secrets, the accumulability of technical capabilities, etc. The increase in productivity expected from imitation is defined as an inverse function of the distance between the current productivity of the firm and that corresponding to the best technological practice in the sector.

49 Although Dosi and Fabiani work with two sectors, in the present case we posit the existence of only a single sector in the economy, in order to simplify the presentation of the model.

${ }^{50}$ The average competitiveness is defined as the sum of the competitiveness of all firms $i$ of all countries $j$ selling their goods on market $k$, weighted by the respective market share of each firm $i$ in market $k$. $E m^{k}$ takes account of the competitiveness of all the firms operating in a given national market. 
Equation (4) is the core of the model's dynamic. If the competitiveness of a firm is below the average, it will lose participation in the market. Parameter $a_{3}$ represents the "selectivity" of the market, that is to say, the speed with which the rewards and punishments imposed by the market are distributed. The total sales of the firm will be given by the following equation:

$$
Y_{i j}(t)=\Sigma_{k} f_{i j}^{k} \cdot D^{k}(t-1) \cdot \rho_{j}(t)
$$

where $D^{k}$ is the total demand in market $k .^{51}$

If the sales of all the firms of a country $j$ in both the external and domestic markets are added together and then divided by the level of prices in $j$, this will give the real national product of $j$ :

$$
Y_{i j}^{*}(t)=\Sigma_{i}\left[Y_{i j}(t) / P_{j}(t)\right]
$$

As already noted, exports are represented by the sales of all the firms of country $j$ in markets $k$ other than that of $j$, while imports are represented by the sales in country $j$ of all the firms based in other countries. The trade balance is thus defined as:

$$
\begin{array}{ll}
B C=X-M & \\
X=\sum_{i k} f^{k} \cdot D^{k}(t-1) \cdot \rho_{j}(t) & \forall k \text { different from } j \\
M=\Sigma_{i} f^{j}{ }_{i k} \cdot D^{j}(t-1) \cdot \rho_{j}(t) & \forall k \text { different from } j
\end{array}
$$

Imbalances in the trade balance are reflected in adjustments in the exchange rate. At the same time, wages are adjusted in response to changes in the level of employment, prices and productivity in the previous periods. ${ }^{52}$ These are feedback mechanisms which compensate (at least partially) for the tendency to market concentration involved in the accumulability of technological capabilities.

\section{Bibliography}

Aghion, P. and P. Howitt (1992): A model of growth through creative destruction, Econometrica, vol. 60, No. 2, Evanston, Illinois, The Economic Society.

Amable, B. (1994): National effects of learning, international specialization and growth paths, in D. Foray and C. Freeman (eds.), Technology and the Wealth of Nations, London, Pinter Publishers.

Barro, R.J. and X. Sala-i-Martin (1995): Economic Growth, New York, McGraw-Hill, Inc.

Bielschowsky, R. (1988): Pensamento econômico brasileiro: o ciclo ideológico do desenvolvimentismo, Rio de Janeiro, Institute of Applied Economic Research (IPEA), Research Institute.

${ }^{51}$ As fixed capital does not exist in the model, it is assumed that the total demand of country $k$ will be given by the wage bill of that country, $D T^{j}=\Sigma_{i} w_{j} \cdot N_{i j}$, where $N_{i j}=N p+N(R \& D)$ is total employment, including both employment in direct production $(N p)$ and employment in research $(N(R \& D))$. Production decisions are taken on the basis of the orders received in the preceding period. For this reason, demand appears with a time-lag of one period.
Canuto, O. (1995): Competition and endogenous technological change: An evolutionary model, Revista brasileira de economia, vol. 49, No. 1, Rio de Janeiro, Getúlio Vargas Foundation.

Cimoli, M. (1988): Technological gaps and institutional asymmetries in a north-south model with a continuum of goods, Metroeconomica, vol. 39, No. 111, Bologna, Italy, Capelli Editore.

Dosi, G. (1988): Sources, procedures, and macroeconomic effects of innovation, Journal of Economic Literature, vol. XXVI, No. 3, Nashville, Tennessee, American Economic Association.

Dosi, G. and S. Fabiani (1994): Convergence and divergence in the long-term growth of open economies, in

\footnotetext{
52 The following equation explains the dynamic of nominal wages: $\Delta w_{j}(t, t+1)=a_{4 j} . \Delta \pi^{e}{ }_{j}(t-1, t)+a_{5 j} . \Delta P^{e}{ }_{j}(t-1, t)+a_{6 j}$. $\Delta N_{j}(t-1, t)$, where $\pi^{e}$ represents the average productivity of the economy weighted by the real product of each firm, $P^{e}$ represents the consumer price index, and the values of parameters $a_{4}$, $a_{5}$ and $a_{6}$ are between 0 and 1 .
} 
G. Silverberg and L. Soete (eds.), The Economics of Growth and Technical Change: Technologies, Nations, Agents, Aldershot, United Kingdom, Edward Elgar.

ECLAC (Economic Commission for Latin America and the Caribbean) (1990): Changing production patterns with social equity, LC/G. 1601-P (SES. 23/4), Santiago, Chile, March.

- 1992): Education and knowledge: Basic pillars of changing production patterns with social equity, LC/G. 1702/Rev. 2-P, Santiago, Chile, August.

(1995): Latin America and the Caribbean: Policies to improve linkages with the global economy, LC/G.1800/Rev. 1-P, Santiago, Chile, April.

(1996): Strengthening development: The interplay of macro- and microeconomics, LC/G.1898/Rev. 1-P, Santiago, Chile, March.

Fagerberg, J. (1988): International competitiveness, The Economic Journal, vol. 98, No. 391, Oxford, United Kingdom, Basil Blackwell.

Fajnzylber, F. (1983): La industrialización trunca de América Latina, Mexico City, Editorial Nueva Imagen.

- (1988): International competitiveness: agreed goal, hard task, CEPAL Review, No. 36, LC/G.1537-P, Santiago, Chile, ECLAC.

(1990): Industrialization in Latin America: from the "black box" to the "empty box", "Cuadernos de la CEPAL" series, No. 60, LC/G.1534/Rev.1-P, Santiago, Chile, ECLAC.

Furtado, C. (1985): Fantasia organizada, Coleção Estudos brasileiros, vol. 89, Rio de Janeiro, Paz e Terra.

Grossman, G.M. and E. Helpman (1991): Innovation and Growth in the Global Economy, Cambridge, Massachusetts, The MIT Press.

- (1994): Endogenous innovation in the theory of growth, The Journal of Economic Perspectives, vol. 8, No. 1, Nashville, Tennessee, American Economic Association.

Jones, L. and R. Manuelli (1990): A convex model of equilibrium growth: Theory and policy implications, Journal of Political Economy, vol. 98, No. 5, Chicago, Illinois, The University of Chicago Press.

Krugman, P. (1992a): Toward a counter-counterrevolution in development theory, Proceedings of the World Bank Annual Conference on Development Economics, 1992, Washington, D.C., World Bank.

(1992b): Motivos y dificultades en la política industrial, Política industrial, teoría y práctica, Madrid, Colegio de Economistas.

Lane, D. A. (1993): Artificial worlds and economics: Part II, Journal of Evolutionary Economics, vol. 3, No. 1, Berlin, Springer-Verlag GmbH \& Co KG.

Lucas, R. (1988): On the mechanics of economic development, Journal of Monetary Economics, vol. 22, No. 1, Amsterdam, Netherlands, NorthHolland Publishing Company, July.

Mankiw, N., D. Romer and D. Weil (1992): A contribution to the empirics of economic growth, Quarterly Journal of Economics, vol. CVII, No. 2, Cambridge, Massachusetts, The MIT Press.

McCombie, J.S. and A.P. Thirlwall (1994): Economic Growth and the Balance of Payments Constraint, New York, St. Martin's Press.

Nelson, R. (1994): Economic growth via the co-evolution of technology and institutions, in L. Leydesdorff and P. Van den Besselaar (eds.), Evolutionary Economics and Chaos Theory, New York, St. Martin's Press.

OECD (Organization for Economic Cooperation and Development) (1992): Technology and the Economy: The Key Relationships, Paris.

Possas, M. (1988): Racionalidade e regularidades: rumo a uma integração micro-macrodinâmica, Campinas, Brazil, Universidade Estadual de Campinas, Instituto de Economia.

Prebisch, R. (1962): The economic development of Latin America and its principal problems, Economic Bulletin for Latin America, vol. VII, No. 1, Santiago, Chile, ECLAC.

-(1973): Economic development, planning and international cooperation, Santiago, Chile, ECLAC.

Ramsey, F. (1928): A mathematical theory of savings, The Economic Journal, vol. 38, London, Macmillan and Co., Ltd., December.

Rebelo, S. (1991): Long-run policy analysis, and long-run growth, Journal of Political Economy, vol. 99, No. 3, Chicago, Illinois, The University of Chicago Press.

Rodríguez, O. (1981): La teoría del subdesarrollo de la CEPAL, Mexico City, Siglo XXI.

Romer, P. (1990): Endogenous technical change, Journal of Political Economy, Chicago, Illinois, The University of Chicago Press.

(1993): Idea Gaps and Object Gaps in Economic Development, Washington, D.C., World Bank.

Solow, R. (1956): A contribution to the theory of economic growth, Quarterly Journal of Economics, vol. LXX, No. 1, Cambridge, Massachusetts, Harvard University.

(1957): Technical change and aggregate production function, Review of Economic Statistics, vol. 39, No. 3, Cambridge, Massachusetts, Harvard University Press.

Vercelli, A. (1991): Methodological Foundations of Macroeconomics: Keynes and Lucas, Cambridge, Massachusetts, Cambridge University Press.

Verspagen, B. (1993): Uneven Growth Between Interdependent Economies, Aldershot, United Kingdom, Avebury. 